\title{
Using TRIZ Techniques to New Product Function Development of Smart Phones
}

\author{
Long-Sheng Chen ${ }^{\dagger}$ \\ Department of Information Management, Chaoyang University of Technology \\ 168 Jifong E. Rd., Wufong Township, Taichung County 41349, Taiwan \\ E-mail:1schen@cyut.edu.tw \\ Shih-Hsun Chen \\ Department of Information Management, Chaoyang University of Technology \\ 168 Jifong E. Rd., Wufong Township, Taichung County 41349, Taiwan \\ E-mail: s9814623@cyut.edu.tw
}

Received, February 25, 2011; Accepted, August 6, 2011

\begin{abstract}
Recently, the fast development of communication technologies has brought a great convince for human beings' life. Lots of commercial services and transactions can be done by using mobile communication equipments such as smart phones. Consequently, smart phones have attracted lots of companies to invest them for their potential growth of market. Compared with basic feature phone, a smart phone can offer more advanced computing ability and connectivity. However, based on the responses of customers, there still are many defectives such as not friendly and smooth operation, short standby time of batteries, threat of virus infected and so on needed to be improved. Therefore, this study will propose a product innovative function development procedure into TRIZ (theory of inventive problem solving) to transform voice of customers into product design and to create novel functions, respectively. A case study of smart phones will be provided to illustrate the effectiveness of the proposed method.
\end{abstract}

Keywords: New Product Development, TRIZ, Smart Phones, Voice of Customer

\section{INTRODUCTION}

Communication technologies have brought human beings convenient life. In particular, the emergence of mobile phones changes lots of business models. Nowadays, commercial services and transactions can be done by using mobile communication equipments such as smart phones. According to the report of Canalys, in the first quarter of 2010, sales of smart phones reached 55.2 million units. Compared with sales in 2009, the amount increases up to $67 \%$ and it's the highest rise since 2007 . Coda Research Consultancy also forecasted that the global smart phone sales will reach 2.5 billion units from 2010 to 2015 . And in this period, it will have $24 \%$ compound growth rate per year, shown in Figure 1. Compare with the basic function of traditional cellular phone, the smart phone can provide more advanced ability of calculate and intercommunication.

Consequently, smart phones have attracted lots of companies to invest them for their potential growth of market.
However, based on the responses of customers, there still are many defectives such as not friendly and smooth operation, short standby time of batteries, threat of virus infected and so on needed to be improved. These defects might result in inconvenience for customers. Smart phones manufacturers need to pay attention on them and make a great improvement.

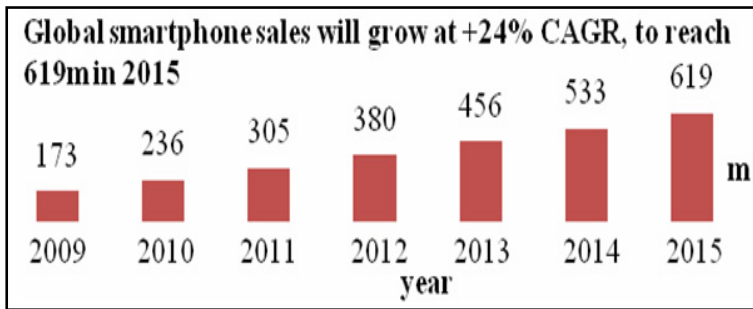

Figure 1. Global smart phone sales (Coda, 2010).

Therefore, this study will propose an innovative product function development procedure by applying TRIZ (theory of inventive problem solving) (Altshuller,

$\uparrow$ : Corresponding Author 
1996) including the Contradiction Matrix Analysis Table and Substance Field Analysis Model Theory to transform voice of customers into product design and to create novel functions, respectively. A case study of smart phones will be provided to illustrate the effectiveness of the proposed method.

\section{RELATED WORKS}

\subsection{New Product Development}

Due to the fierce competition in global markets, to keep developing new products/services is the only way for survival. Therefore, related researchers attempt to develop new service creation models for solving these issues. For examples, Lee et al. (2009) utilized morphological analysis to model a complex problem and discover potential alternatives. Then, they used genetic algorithms to solve built models and find feasible solutions. Hsiao and Liu (2004) combined fuzzy linguistic variables, back propagation neural networks and Analytic Hierarchy Process to identify the relative importance of customer requirements. In the work of Bose and Mahapatra (2001), Case-Based Reasoning is used to enhance the effectiveness of the development system. Kwong et al. (2009) employed Neuro-Fuzzy method to describe explicit customer satisfication and based its result to develop new products. In the work of Yamashina et al. (2002), Quality Function Deployment (QFD) has been used to understand the voice of customers regarding products, and relate them to technical characteristics.

\subsection{TRIZ}

TRIZ has widely applied to automatic classification of patent documents, automated manufacturing systems, chemical engineering, eco-innovation, and so on ( $\mathrm{Li}$ and Huang, 2009; Fresner et al., 2010; Robles et al., 2008). TRIZ has been developed by Altshuller and his colleagues from 1946 (Kim et al., 2009). In 1965, Altshuller analyzed more than 400,000 patents worldwide (Cong and Tong, 2008) and then presented this theory. TRIZ denotes the Russian's abbreviation "Teoriya Reshniya Izobretatelskikh Zadatch." It means "Theory of Inventive Problem Solving" in English. The first article about TRIZ published in 1956 (Chang and Ko, 2006). TRIZ techniques includes Substance Field Analysis Model, Seventy-six Standard Solutions, Contradiction Matrix analysis, 40 principles of innovation, 39 parameters, Algorithm for Inventive-Problem Solving, Step back from IFR, Modeling with "smart little people" and other tools. Users can select appropriate tools to solve their problem depending on type of problems.

Recently, TRIZ has been proven to be a well-structured and innovative way to solve problems in both technical and non-technical areas. In addition, the strength of TRIZ is to develop creative solutions to problems by removing contradictions, instead of using trade off options. And TRIZ offers a well-structured and highpower inventive problem solving process ( $\mathrm{Su}$ and $\mathrm{Lin}$, 2006). TRIZ overcomes the psychological inertia barrier (Loebmann, 2002). In addition, some researchers think that TRIZ can provide repeatability, predictability, and reliability due to its structure and algorithmic approach (Kim et al., 2009). To sum up, TRIZ solves the question based on logics and data, rather than intuition.

Currently, Europe, Japan, Taiwan and China, compose institute for TRIZ theory, conducting more indepth researches (Chang and Ko, 2006). Therefore, Substance Field Analysis Model (Seventy-six Standard Solutions) and Contradiction Matrix Analysis (40 principles of innovation, 39 parameters) have been used to solve customers' complaints, and then create innovative product function of smart phones based on them.

\subsubsection{Substance Field Analysis Model}

Substance field analysis model invented by Altshuller is used as a functional model for describing the relationship in existing systems or new technologies. Substance could be called "Su." The Su-Field analysis model shown in Figure 2 can assist researchers to diagnose and solve most problems. It possesses an icon-andsymbol system and some transformation rules, and then formed a triangle-type relationship (Chang, 2005).

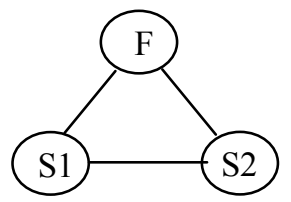

Figure 2. A Typical Su-Field Analysis Model.

Function describes the interaction between substances (elements) and the field (energy). Function has three basic elements, S1, S2, and F. S1 and S2 are specific, that is, "Substance." F is the abstract, called "field," to construct the Substance Field Analysis Model. S1 and S2, such as substance and the tools, objects, human, environment, This classification is based on different levels of an objects hierarchy from a macro- to a microlevel (Kappoth and Goolya, 2008); and F is the mechanical force field (FME), gas field (FP), fluid field $(\mathrm{FH})$, the sound field (FA), etc., as Table 1, As the energy between the two substances.

The term S1 is used to represent an object that needs to be manipulated. The term S2 is a tool to act upon S1 (Mao et al., 2007). Some scholars believe that the SuField analysis provides a fast and simple constructing skill and some transformation rules (Savransky, 2000; Salamatov, 1999; Terninko, 2000). The model can be drawn by some simple graphic icons and symbols (Chang, 2005), such as Table 2. 
Table 1. Field classification (Chang, 2005; Yu and Lau, 2007).

\begin{tabular}{|c|l|c|l|}
\hline Type & \multicolumn{1}{c|}{ Field } & Type & \multicolumn{1}{c|}{ Field } \\
\hline \hline 1. & Mechanical $\left(\mathrm{F}_{\mathrm{ME}}\right)$ & 8. & Magnetic $\left(\mathrm{F}_{\mathrm{M}}\right)$ \\
\hline 2. & Pneumatic $\left(\mathrm{F}_{\mathrm{P}}\right)$ & 9. & Optical $\left(\mathrm{F}_{\mathrm{O}}\right)$ \\
\hline 3. & Hydraulic $\left(\mathrm{F}_{\mathrm{H}}\right)$ & 10. & Gravitational $\left(\mathrm{G}_{\mathrm{V}}\right)$ \\
\hline 4. & Acoustic $\left(\mathrm{F}_{\mathrm{A}}\right)$ & 11. & Biological $\left(\mathrm{F}_{\mathrm{B}}\right)$ \\
\hline 5. & Chemical $\left(\mathrm{F}_{\mathrm{C}}\right)$ & 12. & Nuclear $\left(\mathrm{F}_{\mathrm{N}}\right)$ \\
\hline 6. & Thermal $\left(\mathrm{F}_{\mathrm{T}}\right)$ & 13. & Gravity $\left(\mathrm{F}_{\mathrm{G}}\right)$ \\
\hline 7. & Electrical $\left(\mathrm{F}_{\mathrm{E}}\right)$ & 14. & Radiation $\left(\mathrm{F}_{\mathrm{R}}\right)$ \\
\hline
\end{tabular}

Table 2. Substance Field Analysis Model connection symbols (Altshuller, 1996).

\begin{tabular}{|c|c|}
\hline Symbols & Relationship described \\
\hline & Missing Action \\
\hline & Directed Action \\
\hline --ー-ー-ー- - - & Silence \\
\hline-----------1 & Insufficient Action \\
\hline & Harmful Action \\
\hline$\rightarrow$ & Break of Connection \\
\hline & Transformation \\
\hline$\longrightarrow$ & Interaction \\
\hline$\stackrel{\longrightarrow}{\Rightarrow}$ & Various Actions \\
\hline
\end{tabular}

Table 3. Substance Field Analysis Model classification (Xu and Chen, 2008; Mao et al., 2007).

\begin{tabular}{|c|l|}
\hline Type & \multicolumn{1}{|c|}{ Field } \\
\hline \hline 1. & Effective and complete field \\
\hline 2. & Harmful and complete field \\
\hline 3. & Two-sided and complete field \\
\hline 4. & $\begin{array}{l}\text { A complete system that requires improvement to } \\
\text { create or enhance certain useful impact }\end{array}$ \\
\hline 5. & $\begin{array}{l}\text { An incomplete system that requires completion or a } \\
\text { new system }\end{array}$ \\
\hline 6. & Self- Harmful and complete field \\
\hline
\end{tabular}

Once a model is created, su-field analysis can first tell if any of the three elements of the model is missing or if there are undesired effects in the system (Mao et al., 2007). There are mainly five types of relationship among the substances. They are useful impact, harmful impact, excessive impact, insufficient impact and transformation (Savransky, 2000). Among them, useful and harmful interactions are the most common relationships (Mao et al., 2007). There are four steps to improve an existing product. First, analyze the relationships between components of a product. Second, set up the connection graph of a product. Third, find its potential side effects of the components to the product. Finally, put forward improving suggestions according to the types of the substancefield modules. Table 3 summarized common used Sufield analysis models (Xu and Chen, 2008).

\subsubsection{Contradiction Matrix Analysis Table}

Among TRIZ tools, contradiction analysis is the most widely used method to resolve problems by eliminating contradictions of problems ( $\mathrm{Su}$ and $\mathrm{Lin}, 2006$ ). The Contradiction Matrix table shown as Table 4 is composed of 39 by 39 parameters. A pair of getting worse and to be improved parameters corresponds to some principles of 40 invention rules. When using this method, we first search for the appropriate parameters by matching the meaning of each contradiction from the 39 engineering parameters that have been defined in the TRIZ, because may produce the contradiction between parameter and parameter, then through the contradiction matrix, the user can indicate the suitable inventive principles and can suggest ways to generate the ideal solutions ( $\mathrm{Su}$ and $\mathrm{Lin}, 2006$ ). The inventors could be oriented to the most effective solutions directly, thus this method can save additional time and efforts (Tong et al., 2006).

Table 4. Contradiction Matrix Analysis Table (Alshuller, 2002).

\begin{tabular}{|c|l|c|c|c|}
\hline \multicolumn{2}{|c|}{$\begin{array}{c}\text { Characteristic } \\
\text { (worse) } \\
\text { (to be improved) }\end{array}$} & 01. & $\ldots$ & 39. \\
\hline \hline 01. & Weight of a mobile object & & & $\begin{array}{c}35,03, \\
24,37\end{array}$ \\
\hline$\cdots$ & & & & \\
\hline 15. & $\begin{array}{l}\text { Time of action of a moving } \\
\text { object }\end{array}$ & $\begin{array}{c}19,05, \\
34,31\end{array}$ & & $\begin{array}{c}35,17, \\
14,19\end{array}$ \\
\hline$\cdots$ & & & & \\
\hline 39. & Productivity & 35,26, & & \\
\hline
\end{tabular}

\section{EMPLOYED METHODS}

This section will introduce two used TRIZ techniques including Substance Field Analysis Model and Contradiction Matrix Analysis. By using these techniques, we can transfer customer complaints to innovative product functions.

\subsection{Implemental Procedure of Substance Field Analysis Model}

This section will briefly describe the implemental procedure of Substance Field Analysis Model step by step. Actually, there are 10 steps which can be described as bellow when implementing substance field analysis model. 
Step1: Define problems.

Step2: List all possible substances with the field elements regarding the defined problems.

Step3: Establish initial substance field analysis models related the defined problems.

Step4: Analyze every model and attempt to find the core model to solve the core of defined problems.

Step5: Determine that the model structure is complete or not. If the answer is NOT, use seventy-six standard solutions.

Step6: Analyze if substances and filed are harmful to the model or not. If the answer is YES, use seventysix standard solutions.

Step7: Determine the built model can solve the defined problems or not. If it CAN NOT, use seventy-six standard solutions.

Step8: Can we improve efficiency of the built model? If it cannot be improved, go to next step. If it can be improved, refine the model in this step.

Step9: Transform the constructed model to be the final substance field analysis model.

Step 10: Solve the defined problem.

Readers can find more detailed procedure in the work of Chang and Ko (2006).

\subsection{Implemental Procedure of Contradiction Matrix Analysis}

This section will briefly introduce the implemental procedure of contradiction matrix analysis step by step. The procedure of using contradiction matrix

Step 1: Define problem Define the elements of the design that are required to be improved.

Step 2: Analyze problem Map these into the terms of the 39 parameters of the contradiction matrix.

Step 3: Select parameters

- Identify the solution directions that will help remove the problem.

- Identify which elements in these solution directions are in contraction with the feature to be improved.

Step 4: Find invention principles

Map these into the terms of the 39 parameters of contradiction matrix to get pairs of improvingworsening features. Then, find the corresponding invention principles, according to the pair.

Step 5: Develop and evaluate the feasible solutions Develop alternatives according to the corresponding invention principles and evaluate the feasibility.

Readers can find more detailed procedure in the work of Su and Lin (2006).
Table 5. Customer complaints about smart phones.

\begin{tabular}{|c|l|}
\hline Rank & \multicolumn{1}{|c|}{ Customers' complaints } \\
\hline \hline 1. & $\begin{array}{l}\text { Sweat could affect the smooth operation of } \\
\text { touch panel. }\end{array}$ \\
\hline 2. & $\begin{array}{l}\text { Bluetooth communication functions have been the } \\
\text { channels of virus infected. }\end{array}$ \\
\hline 3. & $\begin{array}{l}\text { Lots of applications and functions have been } \\
\text { included in phones, but they are not easily to be } \\
\text { re-ached. }\end{array}$ \\
\hline 4. & $\begin{array}{l}\text { Insufficient bandwidth of network results in slow } \\
\text { connection speed. }\end{array}$ \\
\hline 5. & $\begin{array}{l}\text { Flash games did delay the running of operation } \\
\text { system. }\end{array}$ \\
\hline 6. & Standby time of batteries is too short. \\
\hline 7. & It's difficult for operating phones by intuitive. \\
\hline
\end{tabular}

\section{IMPLEMENTATIONS}

Table 5 summarizes customers' complaints collected from blogs, BBS, and other public channels. In this study, we focus on solving the top 2 complaints. The top 1 complaint is that sweat could affect the smooth operation of touch panel. The second place is that Bluetooth communication functions have been the channels of virus infected. TRIZ techniques including substance field analysis and contradiction matrix will be utilized to improve the problems mentioned above.

\subsection{Implementing Substance Field Analysis}

This section will use substance field analysis technique to tackle the first complaint listed in table 5. First, we need to define problems. Touch pads are one of main characteristics of smart phones and this device make phone users to easily control every functions in phones. However, the drawback of touch panel is that sweat will influence the smooth operation. Second, we list all possible substances with the field elements regarding the defined problems. They are electrical $\left(\mathrm{F}_{\mathrm{E}}\right)$, smart phones (S1), user (S2), weather (S3). Third, the initial substance field model can be drawn as Figure 3. We check this substance filed analysis model is complete and then we go to next step.

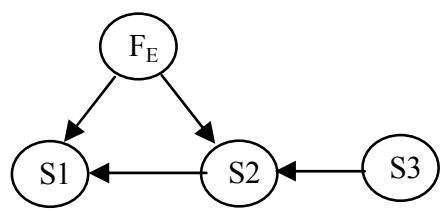

Figure 3. the initial substance field model.

In step 6, as shown in Figure 4, we find S2 (sweat) is harmful to S1 (smart phones). So, we use standard solu- 
tion 5.1.1.4 (Introduce a micro-dose of an extremely active additive) to replace the harmful effect. Consequently, we provide two solutions. The first one is to add a waterproof film (S4) called "protective absorbent film" to the display screen to avoid the harmful effect of sweat. The second one is that smart phone manufacturers could give a special spray (S5) which can generate a thin water-proof film on the surface of display screen and sweat could not stay on the screen. Figure 5 is the final substance field model.

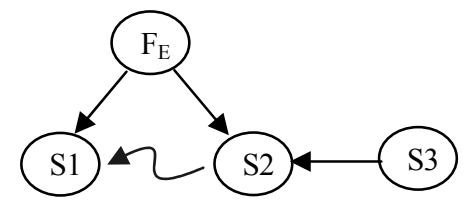

Figure 4. The harmful substance field model.

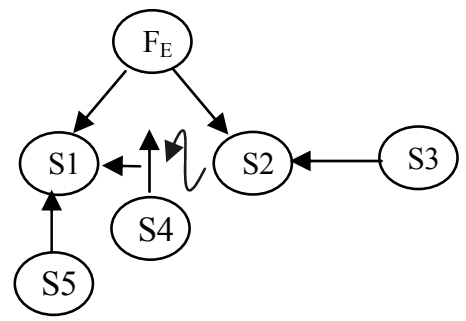

Figure 5. Final substance field analysis model.

In step 6, as shown in Figure 4, we find S2 (sweat) is harmful to S1 (smart phones). So, we use standard solution 5.1.1.4 (Introduce a micro-dose of an extremely active additive) to replace the harmful effect. Consequently, we provide two solutions. The first one is to add a waterproof film (S4) called "protective absorbent film" to the display screen to avoid the harmful effect of sweat. The second one is that smart phone manufacturers could give a special spray (S5) which can generate a thin water-proof film on the surface of display screen and sweat could not stay on the screen. Figure 5 is the final substance field model.

\subsection{Implementing Contradiction Matrix Analysis}

This section will use contradiction matrix analysis technique to tackle the second complaint listed in table 5 . Bluetooth communication functions have been the channels of virus infected. After analyzing the problem, we select several possible engineering parameters to denote the "to be improved" and "to get worse", respectively. In this case, the possible "to be improved" characteristics will be "No. 33: Convenience of use" and "No. 38: Level of automation." The corresponding getting worse parameters are "No. 27: Reliability" and "No. 30 Harmful factors acting on object." Then, to be improved characteristic is "No. 33Convenience of use" because the Bluetooth technology can make the user more convenient to communicate to each other. The getting worse parameter is "No. 30 Harmful factors acting on object parameters" because the Bluetooth feature could not only allow users easily to access data, but also allow hackers to have additional channels to attack systems of smart phones. From contradiction matrix like Table 4, we can find four invention rules. They are "No. 2 Taking out", "No. 25 Self-service", "No. 28 Mechanics substitution", and "No. 39 Inert atmosphere." We take "Taking out" rule to solve this defined problem. The developed solution is "cloud computing". By using cloud computing technologies, we also can keep the advantage of Bluetooth to access data anytime and anywhere. In addition, cloud computing service providers have stronger ability of anti-virus.

Table 6. The created innovative function for smart phones.

\begin{tabular}{|c|c|c|}
\hline Method & Complaints & Solutions \\
\hline \multirow[b]{2}{*}{$\begin{array}{l}\text { Substance } \\
\text { field analysis } \\
\text { model }\end{array}$} & \multirow[b]{2}{*}{$\begin{array}{l}\text { Sweat could affect the } \\
\text { smooth operation of } \\
\text { touch panel. }\end{array}$} & $\begin{array}{l}\text { Add a protective } \\
\text { absorbent film }\end{array}$ \\
\hline & & $\begin{array}{l}\text { Provide a special } \\
\text { spray which can } \\
\text { generate a thin } \\
\text { water-proof film } \\
\text { on the surface of } \\
\text { display screen }\end{array}$ \\
\hline $\begin{array}{l}\text { Contradiction } \\
\text { matrix }\end{array}$ & $\begin{array}{l}\text { Bluetooth } \\
\text { communication } \\
\text { functions have been } \\
\text { the channels of virus } \\
\text { infected. }\end{array}$ & Cloud computing \\
\hline
\end{tabular}

\subsection{SUMMARY}

This research has successfully used substance field analysis model to develop two new functions "protective absorbent film" and "providing a special spray which can generate a thin water-proof film on the surface of display screen" to solve the "sweat" problem. Regarding the virus problem infected from Bluetooth, we employyed contradiction matrix to build a new function "cloud computing" to avoid this problem.

\section{CONCLUSION AND FUTURE WORKS}

In this study, two TRIZ techniques including substance field analysis and contradiction matrix have been employed to create new functions for solving customers' complaints. Three innovative functions of smart phones have been developed. From our experiences of using TRIZ, we find that substance field analysis has some advantages such as (1) 76 standard solutions are more flexible than 40 invention rules, and (2) substance field model can well describe the whole problem. But its disadvantage is not easy to find a solution from a large 
number of standard solutions. Regarding contradiction matrix analysis, if its users can precisely find the improving and worsening parameters, specific innovation principles could be found quickly. However, if no contradiction relation could be found, we cannot use this TRIZ technique.

By the way, some innovative alternatives are usually infeasible during the process of product development. These innovative solutions should be assessed by domain experts. Future works could use Pugh concept selection method to do this job.

\section{ACKNOWLEDGMENT}

This work was supported in part by the National Science Council of Taiwan, R.O.C. (Grant No. NSC 982410-H-324-007-MY2).

\section{REFERENCES}

Altshuller, G. (1996), And Suddenly the Inventor Appeared: TRIZ. Technical Innovation Center (ed).

Altshuller, G. (2002), 40 Principles: TRIZ Keys to Technical Innovation. Technical Innovation Center (ed).

Bose, I. and Mahapatra, R. K. (2001), Business data mining-a machine learning perspective, Information and Management, 39, 211-225.

Chang, H. T. and Chen, J. L. (2004), The conflict-problem-solving CAD software integrating TRIZ into eco-innovation, Advances in Engineering Software, 35, 553-566.

Chang, H. T. (2005), The Study of Integrating Su-Field Analysis Modeling with Eco-Innovative Concept for Product Design, Environmentally Conscious Design and Inverse Manufacturing, Japan, Tokyo, 663670.

Chang, H. T. and Ko Y. C. (2006), The Study of EcoInnovative Design Integrating TRIZ Su-Field Model with Standard Solutions, Chinese Institute of Design, Chinese, Taichung.

Canalys (2010), Global smart phone market growth rises to $67 \%$, http://www.canalys.com/pr/2010/r2010051. html, Access date: 3 May 2005.

Coda Research Consultancy (2010), Worldwide Smartphone Sales Forecast to 2015, http://www.codare search.co.uk/smartphoneworld/index.htm, Access date: 13 May 2010.

Cong, H. and Tong, L. H. (2008), Grouping of TRIZ Inventive Principles to facilitate automatic patent classification, Expert Systems with Applications, 34, 788-795.

Fresner, J., Jantschgi, J., Birkel, S., Barnthaler, J., and Krenn, C. (2010), The theory of inventive problem solving (TRIZ) as option generation tool within cleaner production projects, Journal of Cleaner Pro- duction, 18, 128-136.

Hsiao, S. W. and Liu, E. (2004), A NeuroFuzzy-Evolutionary Approach for Prodct Design, Intergrated Computer-Aided Engineering, 11, 323-338.

Kappoth, P. and Goolya, H. G. (2008), Managing Emotions: Applying the Substance-field Theory, The TRIZ Journal.

Kim, J., Kim, J., Lee, Y., Lim W., and Moon, I. (2009), Application of TRIZ creativity intensification approach to chemical process safety, Journal of Loss Prevention in the Process Industries, 22, 1039-1043.

Kwong, C. K., Wong, T. C., and Chan, K. Y. (2009), A methodology of generating customer satisfaction models for new product development using a neurofuzzy approach, Expert Systems with Applications, 36, 11262-11270.

Loebmann, A. (2002), The TRIZ-Methodology-an always ongoing innovative cycle, The TRIZ Journal.

Li, T. S. and Huang, H. H. (2009), Applying TRIZ and Fuzzy AHP to develop innovative design for automated manufacturing systems, Expert Systems with Applications, 36, 8302-8312.

Lee, C., Song, B., and Park, Y. (2009), Generation of new service concepts A morphology analysis and genetic algorithm approach, Expert Systems with Applications, 36, 12454-12460.

Mao, X., Zhang, X., and AbouRizk, A. (2007), Generalized Solutions for Su-Field Analysis, The TRIZ Journal.

Robles, G. C., Negny, S., and Lann, J. M. L. (2008), Design acceleration in chemical engineerin, Chemical Engineering and Processing, 47, 2019-2028.

Salamatov, Y. (1999), TRIZ: The Right Solution at the Right Time, Insytec B.V (ed).

Savransky, S. D. (2000), Engineering of creativity: introduction to TRIZ methodology of inventive problem solving, CRC Press (ed).

Su, C. T. and Lin, C. S. (2006), A case study on the application of Fuzzy QFD in TRIZ for service quality improvement, Quality and Quantity, 42, 563-578.

Terninko, J., Domb, E., and Miller, J. (2000), The Seventy-six Standard Solutions, with Examples Section One, The TRIZ Journal.

Tong, L. H., Cong, H., and Lixiang, S. (2006), Automatic classification of patent documents for TRIZ users, World Patent Information, 28, 6-13.

Xu, Z. G. and Chen, W. G. (2008), Substance-Field Analysis and Effects for Conceptual Design, Computer-Aided Industrial Design and Conceptual Design, CAD Centre, Shandong Univ., China, 343-348.

Yamashina, H., Ito, T., and Kawada, H. (2002), Innovative product development process by integrating QFD and TRIZ, International Journal of Production Research, 40, 1031-1050.

Yu, K. M. and Lau, C. T. (2007), Practical problem solving by TRIZ enriched with weighted average scoring, International Journal of Product Development, 4, 80-95. 